\title{
Does Corporate Diversification Destroy Value?
}

\author{
JOHN R. GRAHAM, MICHAEL L. LEMMON, and JACK G. WOLF*
}

\begin{abstract}
We analyze several hundred firms that expand via acquisition and/or increase their number of business segments. The combined market reaction to acquisition announcements is positive but acquiring firm excess values decline after the diversifying event. Much of the excess value reduction occurs because our sample firms acquire already discounted business units, and not because diversifying destroys value. This implies that the standard assumption that conglomerate divisions can be benchmarked to typical stand-alone firms should be carefully reconsidered. We also show that excess value does not decline when firms increase their number of business segments because of pure reporting changes.
\end{abstract}

DoEs CORPORATE DIVERSIFICATION destroy value? Several recent papers attempt to answer this question by comparing the market value of firms that operate multiple lines of business to the value of a portfolio of stand-alone firms operating in the same industries as the conglomerate's divisions. Lang and Stulz (1994) use this approach and find that multisegment firms have low values of Tobin's $q$ compared to stand-alone firms. Similarly, Berger and Ofek (1995) find that U.S. conglomerates are priced at a mean discount of about 15 percent. Lins and Servaes (1999) find similar discounts in Japan and the United Kingdom. Indeed, based on the Berger and Ofek methodology, diversified firms with valuation discounts had aggregate value losses of $\$ 800$ billion in 1995 . The magnitude of the value loss suggests that operating the divisions of conglomerates as stand-alone firms would create significant value. In this paper, we provide new evidence on whether the act of corporate diversification destroys value, or whether the divisions that make up conglomerates would trade at a discount, even if they operated as standalone firms.

\footnotetext{
* Graham is from Duke University, Lemmon is from the University of Utah, and Wolf is from Clemson University. We thank three anonymous referees, George Benston, Hank Bessembinder, Judy Chevalier, Rick Green, Owen Lamont, Gordon Phillips, Marlene Plumlee, Henri Servaes, René Stulz, and seminar participants at the 2000 NBER Corporate Finance Summer Workshop, and at Carnegie Mellon, Clemson, Emory, the University of Kentucky, the University of Texas-Austin, the University of Utah, William and Mary, the 2000 meetings of the Western Finance Association and the Southern Finance Association, and the 2001 meeting of the American Economics Association for helpful comments. Graham gratefully acknowledges financial support from the Alfred P. Sloan Research Foundation.
} 
In concluding that diversification destroys value, the prior literature implicitly assumes that stand-alone firms are a valid benchmark for valuing the divisions of conglomerates. The main point of our paper is that the diversification discount calculation can be misleading if there are systematic differences between the divisions of conglomerates and the stand-alone firms to which they are benchmarked. Failure to account for these differences can lead to incorrect inferences regarding the effect of corporate diversification on firm value. To assess the extent to which these selection bias issues are important, we examine two samples of firms that expand via acquisition and/or increase their reported number of business segments.

The first sample consists of firms involved in mergers and acquisitions (M\&A) for which we can identify the market value of the acquirer and target prior to the acquisition. We find that the mean combined announcement return for the acquirer and target is three percent, indicating that overall the market views these mergers positively. Using the methodology of Berger and Ofek (1995), however, the mean excess value of the acquiring firms declines by approximately seven percent over the two-year period surrounding the acquisition. To investigate the source of the decline in excess value, we examine the targets prior to acquisition and find that they have excess values of approximately -10 percent on average in their last year of operation as stand-alone firms. The addition of an already discounted unit reduces the excess value of the acquiring firm as measured by the excess value methodology, even if combining the firms does not destroy any value.

For the M\&A sample, we find that almost all of the seven percent reduction in excess value for the acquirers can be traced directly to the addition of already "discounted" targets. Moreover, the reduction in excess value from the acquisition of a discounted target appears for many different types of firms: (a) those involved in both related and unrelated acquisitions, (b) those that increase their number of segments and those that do not, and (c) those that end up single segment or multisegment after the M\&A event. These findings indicate that in our sample, the units that are combined into other firms are systematically different than stand-alone firms, and suggest that methodologies that benchmark divisions of conglomerates to stand-alone firms might overstate the magnitude of the diversification discount.

Much of the prior literature on the diversification discount (e.g., Lang and Stulz (1994), Berger and Ofek (1995), and Servaes (1996)) defines conglomerates as firms that report operations in multiple business segments. Somewhat surprisingly, only 16 percent of the firms in our M\&A sample increase their number of reported business segments following the merger, even though most of the merger events are large enough to qualify for segment reporting. Chevalier (2000) also finds relatively few segment increases in her M\&A sample. To better understand how our findings for the M\&A sample are related to the multisegment discount, we gather data for a second sample: firms that begin as single-segment and then increase their number of business segments. Nearly two-thirds of these firms increase their number of segments via acquisitions, while the remaining one-third increase their num- 
ber of business segments because of internal expansion or reporting changes. We obtain many more segment increases in this sample, because unlike in the M\&A sample, we include some firms for which we cannot exactly identify the acquired unit prior to acquisition.

For the segment-increasing firms that expand via acquisition, the mean excess value changes from about 0 to -14 percent over the two-year period surrounding the segment increase. Because we cannot directly identify the acquired units in this sample, we assign excess values using a method similar in spirit to the standard benchmarking assumption of the segmentbased literature: To proxy for the excess values of the new segments, we use a multiple of the median value among all same-industry stand-alone COMPUSTAT firms that were targets of completed acquisitions. Our results suggest that about half of the 14 percent "value loss" in these diversifying firms is explained by the parent adding an already discounted unit. We also examine the one-third of firms that increase their reported number of segments because of internal growth or due to pure reporting changes. ${ }^{1}$ These firms do not experience a decline in excess value at the time of the segment increase, which provides additional support for the view that the diversification discount is linked to the characteristics of acquired firms.

Overall, our findings suggest that the benchmarks for valuing conglomerate firms should be carefully chosen, and that one should interpret cautiously conglomerate valuations that rely on comparisons to stand-alone firms. In the conclusion, we discuss strengths and weaknesses related to interpreting our results in the context of the multisegment discount literature.

Several other papers investigate issues related to interpreting the diversification discount. Lang and Stulz (1994), Campa and Kedia (1999), and Hyland (2001) provide evidence that diversifying firms are poor performers prior to conglomeration, indicating that the act of diversifying does not necessarily cause the entire discount observed in conglomerates. Schoar (2000) finds that the industry- $q$ of new units is lower than the average industry- $q$ of a firm's initial segments. Lamont and Polk (2001) show that conglomerate firms have higher required rates of return and that this can account for approximately one-third of the diversification discount. Using plant level data, Maksimovic and Phillips (2002) find that the growth of most conglomerates is consistent with optimal behavior; they do not find evidence that headquarters protects peripheral divisions inefficiently. Whited (2001) argues that much of the evidence that links the diversification discount to inefficient cross-subsidization suffers from problems related to measurement error.

Our paper is also related to other research that examines the endogeneity of the diversification decision. Villalonga (2000) compares conglomerates to

\footnotetext{
${ }^{1}$ Piotroski (1999) finds that firms that increase their number of segments as a pure reporting change (with no real alteration of company structure) exhibit significant positive stock price performance in the periods following the segment increase. Hyland (2001) also distinguishes between reporting changes and other segment-increasing events.
} 
portfolios of single-segment firms with a high "propensity to diversify" (rather than matching to the actual business units that become part of the larger firm like we do in our M\&A analysis). In results similar to ours, she finds that the diversification discount is reduced when conglomerates are compared to stand-alone firms with similar propensities to diversify. In contrast to our paper, however, her focus is on the valuations of diversifying firms and not on the divisions that they add. Our paper also complements the analysis in Chevalier (2000). In a sample similar to our subset of unrelated M\&A firms, she finds that investment patterns commonly attributed to crosssubsidization between divisions are apparent in pairs of merging firms prior to their mergers.

The remainder of the paper is organized as follows. Section I presents a numerical example that summarizes our main point. Section II describes the data. Section III reports ex ante excess values for acquiring and acquired firms, and Section IV shows the extent to which the preacquisition discounts of acquired units explain the change in excess values of the acquiring firms. Section V reports ex ante excess values for segment-increasing firms and those removed from COMPUSTAT because they are acquired, and Section VI relates these figures to the reductions in excess values of the segmentincreasing firms. Section VII summarizes and discusses implications for other corporate diversification studies.

\section{Measuring the Effect of Diversification on Firm Value}

To value multisegment firms, Berger and Ofek (1995) impute values for each segment of a diversified company using valuation multiples from the median stand-alone firm in the same industry as the segment being valued. On average, they find that the actual market value of conglomerates is less than the weighted sum of the imputed divisional values, a negative "excess value." The key assumption in this valuation approach is that "typical" singlesegment firms are a valid benchmark against which to compare the divisions of conglomerates.

The main point of our paper is that a firm's excess value can decline if it acquires an already discounted unit, even if the actual act of combining the units destroys no value. Therefore, conglomeration might not be as bad as is commonly thought. We use a numerical example to illustrate this intuition. Assume that an acquiring firm A with sales of 100 acquires a new unit $\mathrm{T}$ with sales of 65 . The market values of the acquiring and target firms are 115 and 70, respectively, as shown in Table I. To determine the excess value of these firms, we compare each unit's market-to-sales ratio to the benchmark ratio for the median firm in its own industry. The market-to-sales ratio for firm $\mathrm{T}$ is 1.08 in comparison to 1.25 for the median firm in its industry, implying an excess value of -15 percent $(=\ln (1.08 / 1.25))$. In contrast, the excess value of firm $A$ is 0 percent. The rightmost column in Table I shows that the mathematical combination of the two businesses results in an excess value of -6 percent for the conglomerate. 
Table I

\section{Example of Negative Excess Value with No Value Destruction}

This table shows how acquiring target Firm T could affect Firm A's excess value. By construction, total market value is conserved so no market value is destroyed. The benchmark represents the median market-to-sales ratio of single-segment same-industry firms.

\begin{tabular}{lccc}
\hline & Firm A & Firm T & Combination \\
\hline Sales $^{\mathrm{a}}$ & 100.00 & 65.00 & 165.00 \\
Market value & 115.00 & 70.00 & 185.00 \\
Benchmark market-to-sales ratio & 1.15 & 1.25 & 196.25 \\
Imputed value & 115.00 & 81.25 & $-0.06^{\mathrm{c}}$ \\
Excess value & 0.000 & $-0.15^{\mathrm{b}}$ &
\end{tabular}

a This could be book value of assets if an asset multiplier is used.

b Excess value is calculated as $\ln [70 /(65 * 1.25)]=\ln [70 / 81.25]=-0.15$.

${ }^{\mathrm{c}}$ Excess value is calculated as $\ln [(115+70) /(100 * 1.15+65 * 1.25)]=-0.06$.

In this example, the acquisition does not destroy value, and the acquiring firm does not make an inefficient decision when it purchases firm $\mathrm{T}$ at market value. And yet, the excess value calculation makes it appear that the acquirer's value has been reduced by six percent. If, on average, firms that choose to diversify or the divisions that they add are discounted prior to acquisition, then this valuation methodology may erroneously attribute (too much) value loss to the act of combining the two firms. This example highlights that it is important to consider the characteristics of individual divisions of conglomerate firms before concluding (a) that the population of undiversified firms is an appropriate benchmark against which to value conglomerate divisions, and (b) that corporate diversification destroys value.

\section{Sample Selection and Description}

To investigate the potential selection bias issue described above, we examine a sample of firms making acquisitions. We use the Securities Data Corporation (SDC) Mergers and Acquisitions database to identify an initial sample of 2,457 publicly traded acquirers that completed an acquisition of 100 percent of the shares of a publicly traded target firm over the period 1980 to 1995 . We require that both the acquirer and the target are listed in the 1996 active, research, or historical COMPUSTAT Industry Segment files. These files contain segment-level data from 1978 through 1995 and include companies reclassified or removed from the annual industrial files. A total of 755 acquisitions meet these criteria. We refine this sample by applying the same criteria used by Berger and Ofek (1995). We eliminate firm-years with any segment in a financial services industry (SIC code between 6000 and 6999), with total sales less than $\$ 20$ million, or if the sum of segment sales is not within one percent of the firm's total sales. This leaves a sample 
of 356 acquisitions. When assets are not completely allocated across business segments, we prorate the unallocated assets to divisions based on the division's relative asset size.

\section{A. Excess Value Measures}

We define excess value using the two-step methodology in Berger and Ofek (1995). In the first step, an imputed value is calculated for each division by multiplying each segment's sales (assets) by the median market-to-sales (market-to-assets) ratio of single-segment firms in the same industry for the same year. These benchmark multipliers are based on all single-segment firms, including those that are removed from COMPUSTAT due to merger, acquisition, bankruptcy, or other reasons. To ensure that the multipliers are representative, at least five companies in the industry must have data for that year. If less than five firms match at the four-digit SIC level, the threedigit SIC level is examined and so on until the median of the tightest SIC level with at least five observations is found. In the second step, the excess value is calculated as the log of the ratio of the firm's actual market value to the sum of its divisions' imputed values. There are potential valuation problems related to purchase versus pooling accounting when using asset multipliers. ${ }^{2}$ Therefore, in describing our results we focus on sales-based calculations, though we show asset results in the tables.

\section{B. Diversification Measures}

We group firms based on two different measures of the type of diversification. First, if the acquirer and the target share any four-digit SIC codes, according to the COMPUSTAT segment information, we classify the acquisition as related. If the acquirer and target have no common four-digit SIC codes, the acquisition is classified as unrelated. Similar classification schemes are used by Morck, Shleifer, and Vishny (1990) and Chevalier (2000). For our sample, 226 of the acquisitions are unrelated and 130 are related.

Second, we classify the firms according to whether or not the acquisition corresponds to an increase in the number of reported business segments. Fifty-seven of our acquisitions correspond to segment increases as of the year following the acquisition $(t=+1) \cdot{ }^{3}$ Chevalier (2000) also reports few segment

\footnotetext{
${ }^{2}$ With purchase accounting, book asset values are marked-to-market, effectively resulting in a market-to-book asset value of 1.0. This accounting change induces a negative bias into excess value calculations when these altered market-to-book asset ratios for conglomerates are benchmarked to unaltered ratios for stand-alone firms (see Plumlee and Wolf (2000)). The effect of accounting methodology is important in our analysis because half of our sample firms use purchase accounting and we study diversification at the time of acquisition. The issue would exist but be less important if the acquisition had occurred in the more distant past. Importantly, sales are not marked-to-market, so the market-to-sales ratio does not suffer from this same problem.

${ }^{3}$ Another 12 firms record segment increases in year $t=+2$. Using this broader definition of segment increases does not qualitatively alter the reported results.
} 
increases for a similar sample of mergers. The fact that so few acquisitions correspond to segment increases is somewhat surprising, given that more than half of the acquisitions appear to be large enough to warrant reporting as a separate segment (according to the accounting rules described in Section V.A).

Although there are relatively few segment increases directly associated with acquisitions in our sample, 186 of our acquiring firms report operations in multiple business segments in year $t=+1$. Even without segment increases, the fact that over half of the acquirers in our sample are multisegment firms links our results to studies of the conglomerate discount. (Another link, that we discuss in Section V, is that nearly two-thirds of firms that increase from one segment to more than one do so via acquisition.) Finally, because our sample contains a number of firms that remain single-segment following the acquisition, the M\&A sample also allows us to investigate whether the valuation issues we identify apply more generally.

\section{Event Study Returns}

To provide preliminary evidence on the expected valuation effects of the acquisitions in our sample, we compute event study returns over the threeday $\{-1,+1\}$ period surrounding the announcement date of the acquisitions as reported in SDC. The abnormal returns are computed using the residuals from a market model estimated over the period beginning 200 days and ending 51 days prior to the announcement. The mean three-day announcement period cumulative abnormal return of the targets in our sample is 22.51 percent, while for the bidders it is -0.78 percent. The mean combined abnormal returns of the acquirer and target (weighted according to the preannouncement market values of equity) is 3.4 percent. All of these returns are statistically significant at the 0.01 level. We also find positive combined returns in both related and unrelated acquisitions, as well as those that result in single- or multisegment firms ex post. ${ }^{4}$

These abnormal returns are similar to those reported elsewhere. Andrade, Mitchell, and Stafford (2001), Chevalier (2000) and Kaplan and Weisbach (1992) find small negative acquirer returns, large positive target returns, and moderate positive combined returns. Based on the combined returns, these studies and our results indicate that, at the time of the announcement, the market does not view acquisitions as destroying value.

\section{Excess Values of Acquiring and Acquired Firms in the Merger and Acquisition Sample}

In this section we examine the excess values of our merging firms. Because the thrust of our paper is to examine the valuation effects of diversification, we focus on the change in the excess value of the acquirer over the period

\footnotetext{
${ }^{4}$ Like in Morck et al. (1990), the acquiring firms in our M\&A sample experience negative announcement returns in unrelated deals in the 1980s; however, combined returns are positive even for this subset.
} 


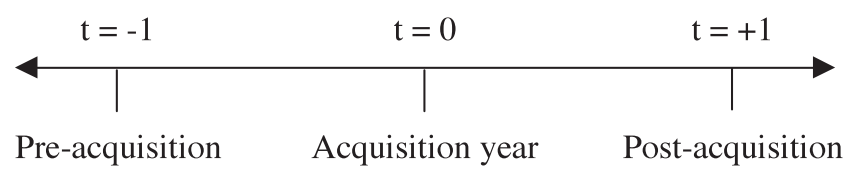

Figure 1. Timing conventions for measuring the change in excess values. We examine the preacquisition $(t=-1)$ to postacquisition $(t=+1)$ change in excess value.

surrounding the acquisition. We require that our sample firms have three years of data available, centered on the year in which the acquisition is completed. The timing conventions are illustrated in Figure 1.

We focus on the first full year after the acquisition $(t=+1)$. We exclude year zero because the excess value measures rely on accounting data, and the effective year of the acquisition $(t=0)$ does not represent a full year of sales revenue for the combined company for the majority of our sample firms.

\section{A. Excess Values of Acquiring Firms}

Table II presents excess values for the acquiring firms in the M\&A sample. For the full sample of 356 firms (Panel A) in the last year in operation as a stand-alone company $(t=-1)$, the mean (median) excess value based on sales multipliers is 14.02 percent (11.03 percent). These excess values are significantly different from zero, indicating that, in the year prior to the acquisition, the acquiring firms are valued at a premium relative to the median single-segment firms in their industries. Chevalier (2000) also finds that acquirers trade at a premium.

By $t=+1$, the first full year after the acquisition, the excess values of the acquiring firms have dropped substantially. The sales multiplier mean (median) excess value is 7.09 percent (6.14 percent). We emphasize that the acquisitions are associated with large declines in excess values. Examining firm-by-firm the change in excess value from $t=-1$ to $t=+1$, the mean (median) change is -6.93 percent $(-4.35$ percent). These changes are statistically significant at the 0.01 level. In unreported analysis, we find that the changes in excess value are uncorrelated with the event study returns documented in Section II.C.

Panels B through E of Table II explore whether the reductions in excess value are related to the type of diversification strategy. Among firms making related acquisitions (Panel B), the mean (median) sales multiplier change in excess value from $t=-1$ to $t=+1$ is -10.44 percent $(-7.75$ percent), significantly different from zero at the 0.01 level. In contrast, firms that make unrelated acquisitions (Panel $\mathrm{C}$ ) exhibit much smaller changes in excess value. For the unrelated acquisition group, the mean (median) change in excess value is -4.92 percent ( -1.62 percent), and only the mean is reliably different from zero at the 0.10 level. Comparing the changes in excess value across the related and unrelated acquisition groups, only the median change based on asset multipliers is statistically different across the two groups at the 0.10 level. 


\section{Table II}

\section{Excess Values for Acquirers}

This table reports excess values for the year prior to and the year following the acquisition. The sample consists of 356 firms that completed acquisitions between 1980 and 1995 with sufficient data to calculate excess values as defined in Berger and Ofek (1995). Acquisitions are classified as related when the acquirer and target firms share a four-digit SIC code prior to the acquisition. Acquisitions are classified as segment increasing if the number of reported segments is greater at $t=+1$ than at $t=-1$. Differences $\left(E V_{+1}-E V_{-1}\right)$ are the firm-specific differences from period $t=-1$ to period $t=+1$. Panel A reports results for the full sample. Panels B through E examine subsamples. Statistical significance for means is based on Robust-Cluster standard errors and statistical significance for medians is based on the Wilcoxon sign-rank test.

\begin{tabular}{|c|c|c|c|c|}
\hline & \multicolumn{2}{|c|}{ Sales Multiplier } & \multicolumn{2}{|c|}{ Asset Multiplier } \\
\hline & Mean & Median & Mean & Median \\
\hline \multicolumn{5}{|c|}{ Panel A: Full Sample (356 firms) } \\
\hline$E V_{-1}$ & $0.1402^{* * *}$ & $0.1103 * * *$ & $0.0753 * *$ & $0.0214 * * *$ \\
\hline$E V_{+1}$ & $0.0709 * *$ & $0.0614^{* * *}$ & 0.0183 & -0.0334 \\
\hline$E V_{+1}-E V_{-1}$ & $-0.0693^{* * *}$ & $-0.0435^{* * *}$ & $-0.0570 * * *$ & $-0.0379 * * *$ \\
\hline
\end{tabular}

Panel B: Related Acquisition (130 firms)

\begin{tabular}{|c|c|c|c|c|}
\hline$E V_{-1}$ & $0.1749^{* * *}$ & $0.1026^{* * *}$ & $0.0712^{* *}$ & $0.0255^{* *}$ \\
\hline$E V_{+1}$ & 0.0705 & $0.0000 * * *$ & -0.0198 & -0.0378 \\
\hline$E V_{+1}-E V_{-1}$ & $-0.1044^{* * *}$ & $-0.0775^{* * *}$ & $-0.0909 * * *$ & $-0.0847 * * *$ \\
\hline
\end{tabular}

Panel C: Unrelated Acquisition (226 firms)

\begin{tabular}{|c|c|c|c|c|}
\hline$E V_{-1}$ & $0.1203 * *$ & $0.1185^{* * * *}$ & $0.0776^{* *}$ & $0.0173^{* *}$ \\
\hline$E V_{+1}$ & 0.0711 & $0.0730 * *$ & 0.0402 & -0.0327 \\
\hline$E V_{+1}-E V_{-1}$ & $-0.0492^{*}$ & -0.0162 & $-0.0374^{*}$ & -0.0169 \\
\hline
\end{tabular}

\begin{tabular}{|c|c|c|c|c|}
\hline \multicolumn{5}{|c|}{ Panel D: No Segment Increase (299 firms) } \\
\hline$E V_{-1}$ & $0.1525^{* * *}$ & $0.1230 * * *$ & $0.0920 * * *$ & $0.0410^{* * *}$ \\
\hline$E V_{+1}^{-1}$ & $0.0971^{* * *}$ & $0.0833 * * *$ & 0.0345 & -0.0207 \\
\hline$E V_{+1}-E V_{-1}$ & $-0.0554^{* *}$ & $-0.0313^{* *}$ & $-0.0576^{* * *}$ & $-0.0378^{* * *}$ \\
\hline
\end{tabular}

\begin{tabular}{|c|c|c|c|c|}
\hline \multicolumn{5}{|c|}{ Panel E: Segment Increase (57 firms) } \\
\hline$E V_{-1}$ & 0.0974 & 0.0912 & -0.0126 & -0.0193 \\
\hline$E V_{+1}$ & -0.0554 & $-0.0855^{*}$ & $-0.0665^{* * *}$ & $-0.0918 * * *$ \\
\hline$E V_{+1}-E V_{-1}$ & $-0.1528^{* *}$ & $-0.1210^{* * *}$ & -0.0539 & -0.0381 \\
\hline
\end{tabular}

$*$, **, and $* * *$ indicate significantly different from zero at the 10,5 and 1 percent levels, respectively.

For acquisitions in which the number of reported business segments remains unchanged (Panel D), the mean (median) change in excess value from $t=-1$ to $t=+1$ is -5.54 percent $(-3.13$ percent), both of which are signif- 
icantly different from zero at the 0.05 level. When the acquisition is accompanied by an increase in the number of reported business segments (Panel $\mathrm{E})$, the decline in excess value is considerably larger. For the segmentincreasing group, the mean (median) change in excess value is -15.28 percent (-12.10 percent), both significantly different from zero. We cannot, however, reject the hypothesis that the changes in excess value are equal at the 0.10 level for the segment-increasing and no-segment-increase groups.

In summary, the acquiring firms in our sample experience a reduction in excess value following the acquisition. One possible interpretation is that acquisitions destroy value. An alternative explanation is that the addition of an already discounted unit causes a decline in the excess value measure, even if no value is destroyed in the acquisition. To investigate this possibility, we study the characteristics of the acquired firms to see what role they play in explaining the decline in excess value.

\section{B. Excess Values of Target Firms}

Table III presents summary statistics of the excess values of the target firms in the M\&A sample prior to acquisition. We compute the excess values using the market value of equity based on the last stock price available prior to delisting. This measure includes the valuation effects of the acquisition announcement.

For the full sample, based on sales multipliers, the mean (median) excess value of the targets is -10.16 percent $(-7.68$ percent), and both are significantly less than zero at the 0.01 level. ${ }^{5}$ These findings indicate that target firms in acquisitions are poor performers (in terms of excess value) relative to "typical" stand-alone firms. The table also reports the relative size of the acquisition, calculated as the ratio of target sales to the combined sales of the acquirer and target at $t=-1$. The acquisitions are fairly large. The mean (median) ratio of target to combined sales is 24.87 percent (21.21 percent). Given the negative excess values of the targets, it is natural to expect that the excess value of the acquiring firms will decline as these fairly large, poorly performing companies are merged into existing operations, even if the acquisitions do not destroy value.

Panels B through E report excess values and relative acquisition sizes for the various subgroups. The most striking result is that the patterns in target firm excess value and relative size in Table III closely parallel the declines in acquiring firm excess value documented in Table II. Namely, target firms in related acquisitions are larger and more deeply discounted relative to targets in unrelated acquisitions. In the related acquisition group (Panel B), the mean sales multiplier excess value of the target firms is -20.58 percent. In comparison, the corresponding mean excess value in the unrelated acqui-

\footnotetext{
${ }^{5}$ We also compute excess values using the market value of equity one month prior to the acquisition announcement. The mean (median) preannouncement excess value of the targets is -35.89 percent ( -35.11 percent). The difference in the preannouncement and the postannouncement excess values shown in the tables reflects the large wealth gains of target shareholders in acquisitions.
} 


\section{Table III}

\section{Excess Values for Targets and Relative Sizes of Acquisitions}

This table reports excess values of target firms in the year prior to being acquired. The sample consists of 356 firms that were acquired between 1980 and 1995 with sufficient data to calculate excess values as defined in Berger and Ofek (1995). The excess value is based on the last stock price available prior to the date the target is delisted. The relative size of the acquisition is the ratio of the target's sales (assets) to the combined sales (assets) of the target and acquirer at the end of the year preceding the acquisition. Acquisitions are classified as related when the acquirer and target firms share a four-digit SIC code prior to the acquisition. Acquisitions are classified as segment increasing if the number of reported segments is greater at $t=+1$ than at $t=-1$. Panel A reports results for the full sample while Panels B through E examine subsamples. Statistical significance for means is based on Robust-Cluster standard errors and statistical significance for medians is based on the Wilcoxon sign-rank test.

\begin{tabular}{|c|c|c|c|c|}
\hline & \multicolumn{2}{|c|}{ Sales Multiplier } & \multicolumn{2}{|c|}{ Asset Multiplier } \\
\hline & Mean & Median & Mean & Median \\
\hline \multicolumn{5}{|c|}{ Panel A: Full Sample (356 firms) } \\
\hline$E V_{-1}$ & $-0.1016^{* * *}$ & $-0.0768 * * *$ & -0.0120 & -0.0268 \\
\hline Relative size & 0.2487 & 0.2121 & 0.2273 & 0.1774 \\
\hline
\end{tabular}

Panel B: Related Acquisition (130 firms)

\begin{tabular}{|c|c|c|c|c|}
\hline$E V_{-1}$ & $-0.2058 * * *$ & $-0.1489 * * *$ & $-0.0765^{* *}$ & $-0.0681^{* * *}$ \\
\hline Relative size & 0.2941 & 0.2697 & 0.2654 & 0.2362 \\
\hline \multicolumn{5}{|c|}{ Panel C: Unrelated Acquisition (226 firms) } \\
\hline$E V_{-1}$ & -0.0417 & -0.0325 & 0.0251 & 0.0000 \\
\hline Relative size & 0.2226 & 0.1577 & 0.2053 & 0.1446 \\
\hline
\end{tabular}

Panel D: No Segment Increase (299 firms)

\begin{tabular}{|c|c|c|c|c|}
\hline$E V_{-1}$ & $-0.1055^{* * *}$ & $-0.0840 * * *$ & -0.0138 & -0.0260 \\
\hline Relative size & 0.2308 & 0.1902 & 0.2125 & 0.1578 \\
\hline
\end{tabular}

\begin{tabular}{|c|c|c|c|c|}
\hline \multicolumn{5}{|c|}{ Panel E: Segment Increase (57 firms) } \\
\hline$E V_{-1}$ & -0.0812 & -0.0768 & -0.0024 & -0.0401 \\
\hline Relative size & 0.3425 & 0.2966 & 0.3048 & 0.2654 \\
\hline
\end{tabular}

** and $* * *$ indicate significantly different from zero at the five and one percent levels, respectively.

sition group is -4.17 percent (Panel C). Additionally, the ratio of target to combined sales of the mean related acquisition (29.41 percent) is larger than that for the mean unrelated acquisition (22.26 percent). Panels $\mathrm{D}$ and $\mathrm{E}$ report the results for the subsamples based on whether the acquisition leads to a segment increase. The mean excess value of target firms in the group with no segment increases is -10.55 percent, compared to a mean excess value of -8.12 percent for targets in acquisitions associated with segment increases. The ratio of target to combined sales of the mean acquisition in 
the no segment increase group is 23.08 percent, compared to a mean of 34.25 percent for the group with segment increases. ${ }^{6}$

The finding that the targets have low excess values is consistent with other research. For example, Hasbrouck (1985) finds that the average $q$-ratio of acquired firms is lower than that of a control group. Lang, Stulz, and Walkling (1989) find that the $q$ ratios of target firms in tender offers decline significantly over the five years preceding the offer. Hubbard and Palia (1999) note that acquired units are often financially constrained. Maksimovic and Phillips (2001) show that acquired plants have lower productivity than the productivity of the selling firm's other plants, and that acquired plants experience subsequent gains in productivity. Schoar (2000) finds that acquired plants have lower productivity than the median plant in their same industry, and that productivity and excess value are positively correlated.

\section{Explaining the Apparent Value Loss in Acquisitions}

In this section, we determine the portion of the reduction in acquiring firm excess value that is attributable to acquiring a unit with low excess value. Our strategy is straightforward. We compute the excess value the combined firm would have if its parts were merged instantaneously at $t=-1$, prior to the actual acquisition. This calculation estimates the excess value of the sum of the combined firm's parts, before the acquisition could have possibly destroyed any value.

More specifically, we define $P_{+1}$, the projected excess value at $t=+1$, as

$$
P_{+1}=\ln \left(\frac{M V A_{-1}+M V T_{-1}}{I V A_{-1}+I V T_{-1}}\right),
$$

where $M V A_{-1}$ and $I V A_{-1}$ are the market value and imputed value of the acquirer at $t=-1$, and $M V T_{-1}$ and $I V T_{-1}$ are the corresponding quantities for the target. The imputed values are calculated using the methodology of Berger and Ofek (1995). We compare the change in the projected excess value to the actual change in excess value of the combined firm to determine whether the acquisition has an effect on the value of the firm, beyond what can be accounted for by the ex ante excess values of the acquirer and the target. ${ }^{7}$

\footnotetext{
6 Though not reported in the tables, we also examine firms that end up as single- or multisegment ex post. In each case, these firms experience decreases in excess value following the acquisition, and the decreases are tied to the size and discount of the acquired unit. The same patterns hold in firms that end up with positive excess value ex post, negative excess value ex post, multisegment and negative excess value ex post, and so forth.

${ }^{7}$ One data issue occurs in some unrelated acquisitions. When an unrelated acquisition does not result in the reporting of a new business segment, the ex post excess value of the combined firm is benchmarked to the industries of the original business segments of the acquirer. The projected excess value, however, is benchmarked in part to the industries of the target's business segments, via $I V T_{-1}$ in equation (1). For these observations, this issue might introduce some noise into the ability of the projected excess value to predict ex post excess values.
} 


\section{Table IV}

\section{Actual and Projected Changes in Excess Values for Acquirers}

This table reports changes in excess values from the year prior to the acquisition to the year following the acquisition. The sample consists of 356 firms that completed acquisitions between 1980 and 1995 with sufficient data to calculate excess values as defined in Berger and Ofek (1995). Statistical significance for means is based on Robust-Cluster standard errors and statistical significance for medians is based on the Wilcoxon sign-rank test.

\begin{tabular}{lccccc}
\hline & \multicolumn{2}{c}{ Sales Multiplier } & & \multicolumn{2}{c}{ Asset Multiplier } \\
\cline { 2 - 3 } & Mean & Median & & Mean & Median \\
\hline Actual change $\left(E V_{+1}-E V_{-1}\right)$ & $-0.0693^{* * *}$ & $-0.0435^{* * *}$ & & $-0.0570^{* * *}$ & $-0.0380^{* * * *}$ \\
Projected change $\left(P_{+1}-E V_{-1}\right)$ & $-0.0738^{* * *}$ & $-0.0176^{* * *}$ & & $-0.0326^{* * *}$ & $-0.0087^{* * *}$ \\
Difference $\left(E V_{+1}-P_{+1}\right)$ & 0.0045 & -0.0133 & & -0.0244 & -0.0168 \\
\hline
\end{tabular}

*** indicates significantly different from zero at the one percent level.

Table IV reports the actual and projected changes in the excess values of the acquiring firms from $t=-1$ to $t=+1$. For the full sample, the mean (median) actual change in excess value based on sales multipliers is -6.93 percent $(-4.35$ percent). The mean (median) projected change is -7.38 percent $(-1.76$ percent). The difference between the actual and projected excess values can be interpreted as the value created or destroyed by acquisition that is not accounted for by the mechanical effect of adding a low valued target. The differences are very close to zero, indicating that the addition of a discounted target explains most of the decline in excess value for the acquirer. ${ }^{8}$

Though not reported in tables, we also analyze various subsamples. For the related acquisition group, the mean (median) differences between the actual and projected changes in excess value are -0.84 percent $(-4.01$ percent). The negative differences suggest that some additional value loss occurs beyond simply adding a low-valued unit; however, neither difference is statistically different from zero. Comparing the unexplained change in excess value to the actual change indicates that the mechanical valuation effect explains approximately 92 percent $(1-[-0.0084 /-0.1044])$ of the mean change in excess value of the acquirers. In the unrelated acquisition group, the mean (median) differences between the actual and projected excess values are 1.19 percent ( 0.71 percent), but neither is significantly different from zero.

For acquisitions with no segment increase, the results are similar to those in the full sample: The mechanical effect of adding a discounted target explains nearly all of the actual change in excess value following the acquisi-

\footnotetext{
8 The finding that there is no significant difference between the value of the pieces and the value of the conglomerate is consistent with a result in Burch and Nanda (2001). In a study of spin-offs, they find that the combined excess value of the parent and spun-off unit is statistically indistinguishable from the excess value of the firm prior to spin-off.
} 


\section{Table V}

\section{Relation Between Projected and Actual Excess Values}

This table reports regression results examining how well the projected excess values actually predict the ex post excess value. The sample consists of 356 firms that completed acquisitions between 1980 and 1995 with sufficient data to calculate excess values as defined in Berger and Ofek (1995). The regression model is:

$$
\left(E V_{+1}-E V_{-1}\right)=\alpha+\beta\left(P_{+1}-E V_{-1}\right)
$$

where $E V_{+1}$ is the actual ex post excess value, $P_{+1}$ is the projected ex post excess value, and $E V_{-1}$ is the ex ante excess value. Robust-Cluster standard errors are presented in parentheses. $P$-values for the null hypotheses that $\alpha=0$ and $\beta=1$ are reported in brackets.

\begin{tabular}{lccc}
\hline & Adj. $R^{2}$ & Intercept & $\begin{array}{c}\text { Coefficient on } \\
\text { Projected Change } \\
\left(P_{+1}-E V_{-1}\right)\end{array}$ \\
\hline Actual change in sales multiplier & 0.2636 & 0.0039 & 0.9968 \\
$\left(E V_{+1}-E V_{-1}\right)$ & & $(0.0190)$ & $(0.1192)$ \\
& & {$[0.839]$} & {$[0.979]$} \\
Actual change in asset multiplier & 0.1516 & -0.0238 & 1.0231 \\
$\left(E V_{+1}-E V_{-1}\right)$ & & $(0.0165)$ & $(0.1044)$ \\
& & {$[0.170]$} & {$[0.827]$} \\
\hline
\end{tabular}

tion. For the segment-increasing subsample, the results are somewhat different. The mean (median) difference in the actual and projected change in excess value is -4.15 percent $(-2.79$ percent). Although these differences are not statistically different from zero, they provide weak evidence that segment-increasing acquisitions exhibit additional value loss beyond that which can be explained by the characteristics of the target. In the case of segment-increasing acquisitions, the mechanical valuation effect explains about 71 percent $(1-[-0.0415 /-0.1428])$ of the average decline in the excess value of the acquirers.

To further explore how much decline in the excess value of acquiring firms is attributable to a purely mechanical effect of adding low valued targets, Table $\mathrm{V}$ presents results from regressing the actual change in excess value on the projected change in excess value. Statistical significance is based on Robust-Cluster standard errors. Using sales multipliers, the $R^{2}$ indicates that the projected change in the value loss explains 26.36 percent of the variation in the actual change. Moreover, the estimated regression coefficient on the projected value loss term is not statistically different from one ( $p$-value $=0.979)$, indicating that the projected change in excess value is an unbiased predictor of the actual change. The intercept in the regression is 0.0039 , which is not statistically different from zero ( $p$-value $=0.839)$. The intercept measures the unexplained portion of the change in excess value and indicates that, on average, essentially no additional value loss remains after accounting for the characteristics of the acquired firm. 


\section{Table VI}

\section{Relation Between Projected and Actual Excess Values}

This table reports regression results examining how well the projected excess values predict actual ex post excess value. The sample consists of 356 firms that completed acquisitions between 1980 and 1995 with sufficient data to calculate excess values as defined in Berger and Ofek (1995). The regression models are:

$$
\left(E V_{+1}-E V_{-1}\right)=\alpha+\beta\left(P_{+1}-E V_{-1}\right)+\lambda I(\cdot)
$$

where $E V_{+1}$ is the actual ex post excess value, $P_{+1}$ is the projected ex post excess value, $E V_{-1}$ is the ex ante excess value, and $I(\cdot)$ is an indicator variable for relatedness or segment increase. The relatedness indicator equals one if the acquisition is classified as related. The segment increase indicator equals one when the acquisition results in an increase in the number of reported business segments. Robust-Cluster standard errors are presented in parentheses. $P$-values for the null hypotheses that $\alpha=0$ and $\beta=1$ and $\lambda=0$ are reported in brackets.

\begin{tabular}{|c|c|c|c|c|}
\hline & Adj. $R^{2}$ & Intercept & $\begin{array}{c}\text { Coefficient on } \\
\text { Projected Change } \\
\left(P_{+1}-E V_{-1}\right)\end{array}$ & $\begin{array}{c}\text { Coefficient on } \\
\text { Indicator Variable } \\
I(\cdot)\end{array}$ \\
\hline \multicolumn{5}{|c|}{ Panel A: Relatedness Indicator } \\
\hline $\begin{array}{l}\text { Actual change in sales multiplier } \\
\qquad\left(E V_{+1}-E V_{-1}\right)\end{array}$ & 0.2620 & $\begin{array}{l}0.0110 \\
(0.0261) \\
{[0.678]}\end{array}$ & $\begin{array}{l}0.9937 \\
(0.1173) \\
{[0.958]}\end{array}$ & $\begin{array}{l}-0.0200 \\
(0.0353) \\
{[0.579]}\end{array}$ \\
\hline $\begin{array}{l}\text { Actual change in asset multiplier } \\
\qquad\left(E V_{+1}-E V_{-1}\right)\end{array}$ & 0.1517 & $\begin{array}{c}-0.0127 \\
(0.0206) \\
{[0.545]}\end{array}$ & $\begin{array}{l}1.0118 \\
(0.1039) \\
{[0.911]}\end{array}$ & $\begin{array}{c}-0.0313 \\
(0.0267) \\
{[0.260]}\end{array}$ \\
\hline \multicolumn{5}{|c|}{ Panel B: Segment Increase Indicator } \\
\hline $\begin{array}{l}\text { Actual change in sales multiplier } \\
\qquad\left(E V_{+1}-E V_{-1}\right)\end{array}$ & 0.2637 & $\begin{array}{l}0.0126 \\
(0.0237) \\
{[0.603]}\end{array}$ & $\begin{array}{l}0.9907 \\
(0.1237) \\
{[0.941]}\end{array}$ & $\begin{array}{l}-0.0579 \\
(0.0541) \\
{[0.302]}\end{array}$ \\
\hline $\begin{array}{l}\text { Actual change in asset multiplier } \\
\qquad\left(E V_{+1}-E V_{-1}\right)\end{array}$ & 0.1500 & $\begin{array}{c}-0.0196 \\
(0.0179) \\
{[0.290]}\end{array}$ & $\begin{array}{l}1.0296 \\
(0.1040) \\
{[0.780]}\end{array}$ & $\begin{array}{c}-0.0254 \\
(0.0303) \\
{[0.415]}\end{array}$ \\
\hline
\end{tabular}

Table VI presents analysis regressing the actual change in excess value on the projected change and two indicator variables. In Panel A, the indicator is set equal to one if the acquisition is related. We include the relatedness indicator because other research has found that unrelated diversification is worse than related diversification (e.g., Berger and Ofek (1995)). Based on sales multipliers, the estimated coefficient on the projected value loss is not significantly different from one $(p$-value $=0.958)$. The estimated intercept is 0.0110 ( $p$-value $=0.678$ ), indicating that for unrelated acquisitions the characteristics of the acquired unit account for almost all of the observed change in excess values. For related acquisitions, the coefficient estimate on the indicator variable is -0.0200 , which is insignificant. 
In Panel $\mathrm{B}$, the indicator variable is set equal to one if the acquisition leads to a segment increase. The coefficient on the segment-increase indicator is -0.0579 , but is not significantly different from zero ( $p$-value $=0.302)$. The negative coefficient on the indicator variable provides weak evidence that segment-increasing acquisitions result in value loss beyond that explained by the characteristics of the target.

Our M\&A evidence shows that the excess values of acquiring firms decline following acquisition, which we attribute to acquired units having significantly negative excess values. This result suggests that the types of firms that are absorbed into other firms differ systematically from the stand-alone firms to which conglomerates are typically benchmarked. By accounting for the preacquisition value of the target firms, we explain most of the negative valuation effects associated with mergers.

On the surface, our not leaving any unexplained reduction in excess value might seem at odds with the evidence of long-term negative drift in acquiring firm stock prices following mergers (e.g., Loughran and Vijh (1997) and Rau and Vermaelen (1998)). Note, however, that there is not necessarily a relation between stock returns and excess value measures. The latter are industry-adjusted ratios of market value to an accounting item. Even if the firm's stock returns decline following the merger, the excess value measure need not decline because the firm's sales or assets (or stock returns of the industry benchmark) may also decline. Moreover, our analysis focuses on the first year following the merger, while the typical long-run returns paper examines between three and five years ex post.

\section{Segment-increasing Firms}

Much of the diversification discount literature defines conglomeration as operation in multiple business segments, and there are relatively few segment increases in the M\&A sample. To comment more directly on the valuation effects associated with operating in multiple business segments, and also to assess the robustness of the M\&A results, we examine a sample of firms that increase their number of business segments from one to more than one. Relative to the M\&A sample, the criteria to be included in the segment-increasing sample are not as restrictive in that we do not require being able to exactly identify the acquired unit(s).

\section{A. Segment-increasing Sample}

From the set of firms listed in the 1996 COMPUSTAT Industry Segment file, including the research and historical files, we identify those that change from reporting one segment (in $t=-1$ ) to reporting multiple segments. We require that these firms have three years of data and that they report more than one segment in periods $t=0$ and $t=+1$. We concentrate on these firms, in part, because Lang and Stulz (1994) and Servaes (1996) show that the largest drop-off in $q$ occurs between single-segment and two-segment 
firms. We also require that the firms meet all of the Berger and Ofek (1995) requirements (as described in Section I). We begin the sample period in 1984 because Lexis/Nexis does not have annual reports for periods earlier than 1984.

Firms increase their number of reported segments for a variety of reasons. Financial Accounting and Standards Board (FASB) Statement 14 requires firms to report data for individual lines of business that represent more than 10 percent of the firm's total revenues, assets, or profits. New segments may result from the acquisition of a new line of business, the internal growth of an operation that passes one of these thresholds, or simple restructuring of existing operations. Based on annual reports, 10-Ks, and Investor Dealers' Digest Merger \& Acquisition reports from Lexis/Nexis, we group our sample firms into three categories related to the reason for the increase in the number of reported business segments.

Under Generally Accepted Accounting Principles (APB 16, August 1970), firms are required to discuss acquisitions in the footnotes of their filings. When the footnotes mention an acquisition, we place a firm into one of two categories. If the acquired unit operates in an industry related to the existing operations of the diversifying firm based on the four-digit SIC code listed in COMPUSTAT, we categorize the segment increase as a related acquisition. Otherwise, the acquisition is classified as unrelated. We delete $32 \mathrm{ob}-$ servations because either the size or industry of the new business segment does not match the description of the acquired firm(s). If we find no evidence of an acquisition, we include the segment increase in the "no acquisition" group. Firms in this group may have added segments due to internal growth, a decision to begin reporting a previously existing division, and so forth.

The majority of segment increases in our sample result from acquisitions. Of the final sample of 225 segment increases, 124 result from unrelated acquisitions, 17 result from related acquisitions, and the remaining 84 segment increases are the result of internal growth and reporting changes. These proportions are similar to those in Hyland (2001), who reports that 150 out of 227 firms in his sample of firms that increase from one segment to more than one segment do so via acquisition.

The primary difference between the M\&A and segment-increasing samples is that in the former we only keep firms for which we can identify the acquired unit. 9 In contrast, in the segment-increasing sample, we do not require exact identification of the acquired unit that leads to the segment increase. In many cases, the segment increases result from partial acquisitions, acquisitions of private firms, or multiple acquisitions that occur over several years.

\footnotetext{
9 Two other differences are that the segment-increasing sample only includes firms that start with a single unit, and the segment-increasing sample contains some firms that increase their number of reported segments, even though they did not make an acquisition (the "no acquisition" group).
} 


\section{Table VII \\ Excess Values for Firms That Increase the Number of Reported Segments}

This table reports excess values for the year prior to and the year following the first year in which more than one segment is reported. The sample consists of 225 firms that changed from reporting one segment in year $t=-1$ to reporting more than one segment in years $t=0$ and $t=+1$. Excess values are calculated as defined in Berger and Ofek (1995). Differences $\left(E V_{+1}-E V_{-1}\right)$ are the firm-specific differences from period $t=-1$ to period $t=+1$. Panel A reports results for the full sample while Panels B through D examine subsamples. Statistical significance for means is based on Robust-Cluster standard errors and statistical significance for medians is based on the Wilcoxon sign-rank test.

\begin{tabular}{|c|c|c|c|c|}
\hline & \multicolumn{2}{|c|}{ Sales Multiplier } & \multicolumn{2}{|c|}{ Asset Multiplier } \\
\hline & Mean & Median & Mean & Median \\
\hline \multicolumn{5}{|c|}{ Panel A: Full Sample (225 firms) } \\
\hline $\begin{array}{l}E V_{-1} \\
E V_{+1}\end{array}$ & $\begin{array}{c}0.0472 \\
-0.0899^{* *}\end{array}$ & $\begin{array}{c}0.0000 \\
-0.0708^{* * *}\end{array}$ & $\begin{array}{c}0.0323 \\
-0.0481^{*}\end{array}$ & $\begin{array}{c}0.0000 \\
-0.0811^{* * *}\end{array}$ \\
\hline$E V_{+1}-E V_{-1}$ & $-0.1371^{* * *}$ & $-0.0707 * * *$ & $-0.0870 * * *$ & $-0.0397 * * *$ \\
\hline \multicolumn{5}{|c|}{ Panel B: No Acquisition (84 firms) } \\
\hline $\begin{array}{l}E V_{-1} \\
E V_{+1}\end{array}$ & $\begin{array}{r}0.0418 \\
-0.0230\end{array}$ & $\begin{array}{r}0.0000 \\
-0.0093\end{array}$ & $\begin{array}{l}-0.0022 \\
-0.0389\end{array}$ & $\begin{array}{r}0.0029 \\
-0.0688\end{array}$ \\
\hline$E V_{+1}-E V_{-1}$ & -0.0648 & -0.0158 & -0.0387 & -0.0195 \\
\hline
\end{tabular}

\begin{tabular}{lcccc}
\hline \multicolumn{4}{c}{ Panel C: Unrelated Acquisitions (124 firms) } \\
\hline$E V_{-1}$ & 0.0330 & 0.0000 & 0.0464 & -0.0080 \\
$E V_{+1}$ & $-0.1326^{* *}$ & $-0.1075^{* * *}$ & $-0.0598^{*}$ & $-0.0874^{* *}$ \\
$E V_{+1}-E V_{-1}$ & $-0.1656^{* * *}$ & $-0.0852^{* * *}$ & $-0.1063^{* * *}$ & $-0.0416^{* *}$ \\
\hline \multicolumn{4}{c}{ Panel D: Related Acquisitions $(17$ firms) } \\
\hline$E V_{-1}$ & 0.1778 & 0.0860 & $0.1781^{*}$ & 0.0080 \\
$E V_{+1}$ & -0.1085 & -0.0324 & -0.0074 & -0.0511 \\
$E V_{+1}-E V_{-1}$ & $-0.2863^{* *}$ & $-0.2216^{* * *}$ & $-0.1855^{* *}$ & $-0.1793^{* * *}$ \\
\hline
\end{tabular}

$*, * *$, and $* * *$ indicate significantly different from zero at the 10,5 , and 1 percent levels, respectively.

\section{B. Excess Values of Segment-increasing Firms}

Table VII presents excess values centered on the year of the segment increase. For the full sample of 225 firms (Panel A) in the last year in operation as a focused company $(t=-1)$, the mean (median) excess value based on sales multipliers is 4.72 percent ( 0.00 percent). These excess values are not significantly different from zero, indicating that, in the year prior to diversifying, the sample firms are not valued at a discount relative to the median single-segment firms in their industries. These results are similar to 
those reported in Lang and Stulz (1994), who find that diversifying firms have industry-adjusted Tobin's $q$ values that are not significantly different from zero. Our results differ from those reported in Campa and Kedia (1999), who find that diversifying firms have negative excess values prior to diversification. ${ }^{10}$

By $t=+1$, the first full year after conglomeration, the diversifying firms exhibit a statistically and economically significant diversification discount. The sales multiplier mean (median) excess value is -8.99 percent ( -7.08 percent), which are reliably negative at the 0.10 level or better. More importantly, diversification is associated with large declines in excess value. Firm by firm, the mean (median) change in excess value from $t=-1$ to $t=+1$ is -13.71 percent $(-7.07$ percent), which are significant at the 0.01 level.

In Panels B through D of Table VII, we examine whether the change in excess value varies by the type of segment increase. Note that much of the existing literature defines diversification based on the number of reported segments. One therefore might expect to observe a decline in excess value whenever a firm begins to report additional segments. In some instances, however, firms begin to report new business segments because of internal growth or a change in filing practice. (For example, Cybex International reports a single segment, "medical and fitness eq." in 1992. In 1993, Cybex operates two segments, "exercise equipment" and "medical equipment." Total assets of the company increased only $\$ 5$ million, from $\$ 104$ million in 1992 to $\$ 109$ million in 1993.) In these "no acquisition" cases, the firm has not changed substantially, even though the number of segments has increased, so we do not expect to find a significant decrease in excess value.

Firms that add segments because of internal growth or reporting changes start with excess values that are indistinguishable from zero and, consistent with our expectation, do not exhibit a significant reduction in excess value (Panel B). The mean (median) sales multiplier change in excess value for the no acquisition group is -6.48 percent $(-1.58$ percent), and neither is reliably different from zero. Therefore, there does not appear to be loss in value when the increase in the number of business segments is attributable to internal growth or reporting changes.

Firms that increase their number of business segments through unrelated acquisitions also have excess values that are indistinguishable from zero prior to diversification, but exhibit large changes in excess value after increasing their number of segments. For the unrelated acquisition group, the mean (median) change in excess value from $t=-1$ to $t=+1$ is -16.56 per-

\footnotetext{
${ }^{10}$ Campa and Kedia (1999) find that firms that diversify once from one to more than one segment trade at a discount of seven percent (two percent) using sales (asset) multipliers in the year prior to the segment increase. One difference between their approach and ours is the choice of benchmark to calculate excess values. Campa and Kedia restrict the benchmark group to firms that always operate as a single segment. In contrast, we assume no foreknowledge of the firms' future choices about whether to operate as a focused or diversified firm and thus avoid any potential look-ahead bias.
} 


\section{Table VIII \\ Excess Values for Single-segment Firms That Are Removed from COMPUSTAT Because of Merger or Acquisition}

This table reports excess values for the three years before the firm was removed from COMPUSTAT due to merger or acquisition. The sample consists of 653 firms that are removed from the COMPUSTAT active tapes because of merger or acquisition over the period 1984 to 1995. Excess values are calculated as defined in Berger and Ofek (1995). Statistical significance for means is based on Robust-Cluster standard errors and statistical significance for medians is based on the Wilcoxon sign-rank test.

\begin{tabular}{|c|c|c|c|c|}
\hline & \multicolumn{2}{|c|}{ Sales Multiplier } & \multicolumn{2}{|c|}{ Asset Multiplier } \\
\hline & Mean & Median & Mean & Median \\
\hline$E V_{-3}$ & $-0.0574 * * *$ & $-0.0511^{* * * *}$ & -0.0020 & -0.0056 \\
\hline$E V_{-2}$ & $-0.1251^{* * *}$ & $-0.1131^{* * *}$ & $-0.0408 * * *$ & $-0.0386^{* * *}$ \\
\hline$E V_{-1}$ & $-0.1596^{* * *}$ & $-0.1601^{* * *}$ & $-0.0593 * * *$ & $-0.0526 * * *$ \\
\hline
\end{tabular}

*** indicates significantly different from zero at the one percent level.

cent (-8.52 percent), both significantly less than zero at the 0.01 level. Companies making related acquisitions have the largest decline in excess value. The related acquisition group has positive excess values in year $t=-1$, and large negative excess values in year $t=+1$. The mean (median) change in sales-based excess value is -28.63 percent $(-22.16$ percent), and both are significantly less than zero at the 0.01 level. This finding is consistent with our results for the M\&A sample, where related acquisitions are associated with large declines in excess values. However, the related acquisition group has only 17 observations, so these numbers should be treated cautiously. ${ }^{11}$

\section{Excess Values of Acquired Firms}

The acquired units in the M\&A sample are valued at a significant discount relative to same-industry stand-alone firms. To examine whether this finding can be generalized, Table VIII presents excess values for the population of firms that are removed from COMPUSTAT because they are acquired. COMPUSTAT footnote number 35 indicates whether firms on the annual industrial files are removed due to acquisition or merger (codes 01 or 04$)$.

\footnotetext{
${ }^{11}$ We statistically reject the hypothesis that the mean and median changes in excess value in Panels B through D are equal across the three groups at the 0.05 level. In pairwise comparisons based on sales multipliers, the mean changes in excess value are not equal for the no acquisition and unrelated acquisition groups at the 0.10 level. The differences in the medians are not significant. The differences in the mean (median) changes in excess values across the no acquisition and related acquisition subsamples are significant at the 0.05 (0.01) level. The differences in the mean changes in excess values across the related and unrelated groups are not significant, but the differences in the medians are significant at the 0.05 level.
} 
Two key points stand out. First, the excess values are significantly below zero in year $t=-1$, just prior to when the firm is acquired. Second, there is a notable downward trend in the years leading up to the firm's acquisition. ${ }^{12}$ The mean excess values based on sales multipliers are -5.74 percent in year $t=-3,-12.51$ percent in year $t=-2$, and -15.96 percent in year $t=-1 .^{13}$ These excess values are all significantly different from zero at the 0.01 level. With discounts of this magnitude, it is natural to expect that the excess value of segment-increasing firms will decline as poorly performing companies are merged into existing operations, even if diversification itself does not destroy value.

\section{Explaining (Part of) the Apparent Value Loss in Segment-increasing Firms}

To determine the portion of the ex post discount for segment-increasing firms that is attributable to the acquisition of a unit with negative excess value, we follow the strategy that we used on the M\&A sample. We project the excess value that the conglomerate would have if its parts were merged instantaneously at $t=-1$, prior to the actual segment increase. The only difference is that, for the sample of segment-increasing firms, we calculate the imputed value of the new segment(s) using the median excess value at $t=-1$ from the population of acquired firms in the same industry. ${ }^{14}$ In other words, we assume that the excess values of the new segments are similar to those of other acquired firms in the same industry, which is similar in spirit to the benchmarking assumption made in other conglomeration analyses. We use the respective actual sizes of the conglomerate segments as of $t=+1$ to weight the $t=-1$ excess values of the initial segment and proxied new segment(s). This calculation determines the projected excess value of the conglomerate after the segment increase, under the null hypothesis that the act of diversification itself does not affect value.

We only perform this calculation for the unrelated acquisition group. The comparison is not feasible for the firms making related acquisitions because the original parent division of these firms is often dissolved in conjunction

\footnotetext{
${ }^{12}$ As noted earlier, Lang et al. (1989) find that the $q$ ratios of target firms in tender offers decline significantly over the five years preceding the offer.

${ }^{13}$ In spite of the decline in the excess values of acquired firms, there is only limited evidence that target firms have low stock returns in the period preceding the acquisition. For example, Agrawal and Jaffe (2001) only find evidence of underperformance in subsamples of target firms involved in acquisitions where disciplining of management is likely. However, as noted previously, there need be no relation between stock returns and excess value measures, because the latter are industry-adjusted ratios of market value to an accounting item.

14 There are only 653 single-segment firms with sufficient data to calculate excess value that are removed from the COMPUSTAT active file because of merger or acquisition during 1984 to 1995, and in many industries, only a few firms are removed. Therefore, for this part of the paper only, we define industry based on one-digit SIC code, to ensure that we have enough acquired firms in any given industry.
} 
Table IX

\section{Regressions of Actual Changes in Excess Value on Projected Changes in Excess Value for Segment-increasing Firms}

This table reports regression results examining how well the projected excess values predict the ex post excess value. The sample consists of 124 firms that changed from reporting one segment at year $t=-1$ to reporting more than one segment during years $t=0$ and $t=+1$ as the result of an unrelated acquisition. Excess values are calculated as defined in Berger and Ofek (1995). The regression model is

$$
\left(E V_{+1}-E V_{-1}\right)=\alpha+\beta\left(P_{+1}-E V_{-1}\right)
$$

where $E V_{+1}$ is the actual ex post excess value, $P_{+1}$ is the projected ex post excess value, and $E V_{-1}$ is the ex ante excess value. Robust-Cluster standard errors are presented in parentheses. $P$-values for the null hypotheses that $\alpha=0$ and $\beta=1$ are reported in brackets.

\begin{tabular}{lccc}
\hline & & $\begin{array}{c}\text { Coefficient on } \\
\text { Projected Change } \\
\left(P_{+1}-E V_{-1}\right)\end{array}$ \\
\hline Actual change in sales multiplier & Adj. $R^{2}$ & Intercept & 0.8192 \\
$\left(E V_{+1}-E V_{-1}\right)$ & 0.3304 & -0.0926 & $(0.0647)$ \\
& & $(0.0363)$ & {$[0.0191]$} \\
$\begin{array}{c}\text { Actual change in asset multiplier } \\
\left(E V_{+1}-E V_{-1}\right)\end{array}$ & 0.3265 & -0.0783 & 0.6797 \\
& & $0.0257)$ & $(0.2179)$ \\
\hline
\end{tabular}

with the increase in the number of reported business segments. Specifically, of the 17 firms making related acquisitions, the segment ID at $t=-1$ of the original parent continues to exist at $t=+1$ for only 6 firms.

To examine how much of the actual value loss is mechanically attributable to the acquisition of a discounted unit, we calculate the actual and projected changes in excess value for the segment-increasing firms (not tabulated). Based on sales multipliers, the mean actual change in excess value from $t=-1$ to $t=+1$ is -16.56 percent, while the mean projected change is -8.91 percent, implying that approximately 50 percent of the observed value loss can be accounted for by the addition of an already discounted unit. Based on asset multipliers, we explain approximately 40 percent of the mean decline in excess value.

Table IX presents results from regressing the actual change in excess value on the projected change. Based on $R^{2}$, the projected change explains 33 percent of the variation in the actual value loss. Moreover, the estimated regression coefficient on the projected value loss term is close to (though statistically different from) 1.0, indicating that the projected value loss estimates do a reasonable job capturing the cross-sectional variation in the actual changes in excess values. The intercept in the regression is -0.0926 , which is significantly different from zero ( $p$-value $=0.029$ ). The intercept indicates that the unexplained portion of the 16.56 percent change in excess value is approximately 9.26 percent. Our results indicate that only about 
one-half of the discount in our sample of segment-increasing firms can be attributed to negative valuation consequences associated with diversification. This result is generally consistent with our findings from the subsample of M\&A firms with segment increases.

Finally, we perform an unreported robustness check to investigate the effect of our proxying for the excess value of the acquired units in the segmentincreasing sample. We repeat the analysis on the M\&A sample pretending that we do not know the identity of the actual acquired unit but instead proxying with the median same-industry single-segment firm among acquired units. ${ }^{15}$ That is, we repeat on the M\&A sample the experiment that we use on the segment-increasing sample (except that we use $t+1$ weights in this robustness check). As in Table V, the adjusted $R^{2}$ for the regression of the actual change in excess value on the projected change is around 20 percent and the beta coefficient is indistinguishable from 1.0; however, the intercept equals -0.049 . Interestingly, when we proxy for the acquired units in the M\&A sample, we do not explain the entire value loss, which corresponds to the pattern we observe when we use the same methodology on the segment-increasing sample. Overall, this suggests that proxying for the acquired unit (as in the segment-increasing analysis) does not induce substantial bias into projecting the change in excess value, although it does reduce the portion of the value loss that we can explain.

\section{Conclusions}

During the 1990s, academic research and popular press reports generally argued that corporate diversification destroys value. Based on methodologies that compare the values of conglomerates to proxies for the valuations of their individual divisions, the literature indicates that conglomerate firms are discounted by as much as 15 percent from the value that could be attained by breaking them up and operating the divisions as stand-alone companies.

An implicit assumption in the common valuation methodologies is that divisions of conglomerate firms are similar to "typical" stand-alone firms. We contend that if the divisions of conglomerates systematically differ from the stand-alone firms to which they are benchmarked, failure to account for these differences can lead to incorrect inferences regarding the valuation effects of corporate diversification. Our evidence suggests that these selection biases are important.

We show that units that are combined into firms through merger or acquisition are priced at significant discounts (relative to the median standalone firm in the same industry) prior to becoming part of the larger firm. When this discounted unit is added to an existing firm, not surprisingly, it has a negative effect on the excess value of the combined business as measured using the standard methodology. In a sample of acquisitions, we dem-

${ }^{15}$ We thank Owen Lamont for suggesting this experiment. 
onstrate that accounting for the characteristics of the acquired units explains nearly all of the reduction in the acquirer's excess values for all types of acquisitions (related or unrelated and segment-increasing or not) and firms (whether they are single- or multisegment ex post). In a sample of segmentincreasing firms, we proxy for the preacquisition discount of acquired units and account for about half of the reduction in excess value following the segment increase. Consistent with the view that the characteristics of acquired units are an important factor in determining the valuation discount, we find that excess value is not reduced when a firm increases its number of business segments without making an acquisition.

A strength of our M\&A analysis is that we are able to directly value the acquired business units. However, our M\&A firms are priced at a premium prior to the acquisition and relatively few acquisitions directly result in segment increases. These facts imply that our results cannot be applied onefor-one to the overall corporate diversification literature; however, we feel that our analysis has important implications for that literature. First, half of our M\&A firms are multisegment ex post, and the valuation of these firms (which are included in typical diversification discount studies) is artificially low according to the standard methodologies because they contain a unit that would be valued at a discount even if it stood alone. Second, nearly two-thirds of the firms that increase their number of segments do so via acquisition in our sample, and only firms that become multisegment via acquisition experience a reduction in excess value. In her broad sample of firms, Schoar (2000) finds that already diversified firms are relatively likely to continue making acquisitions and that they expand more frequently via acquisition than they do via internal growth. These points indicate that corporate diversification is closely tied to the acquisition process and link our M\&A findings to the corporate diversification literature.

A weakness of our segment-increasing analysis is that we cannot explicitly value the acquired units because many segment increases result from partial acquisitions, acquisitions of private firms, or multiple acquisitions. We proxy for the value of the acquired units using information about public firms that become inactive due to merger or acquisition. Our approach is therefore similar to that used in most diversification studies, which use information on publicly traded stand-alone firms to value the divisions of conglomerates. Moreover, Schoar's (2000) analysis implies that, were it available, using valuations of private and partial acquisitions might produce results similar to what we report. Schoar finds that acquired plants (many of which are privately held) have lower productivity than the median plant in their industry and that plant-level productivity is positively related to excess value.

To the extent that our results carry over to the broader sample of conglomerate firms, they have important implications about whether conglomeration destroys value in the typical multisegment firm. At a minimum, our results suggest that the standard assumption that conglomerate divisions can be benchmarked to firms that remain as stand-alone needs to be care- 
fully reconsidered. Moreover, they also suggest that the distribution of excess values for multisegment firms should be centered closer to 0 , instead of near -15 percent as implied by some previous research. Even if the distribution is centered at 0 , however, much research remains to be done explaining the cross-sectional distribution of excess values.

In terms of measuring the diversification discount, we offer a new approach to benchmarking the divisions of conglomerate firms: Compare conglomerate divisions that arise via acquisition to stand-alone firms that disappear from the public record because they are merged or acquired. Other researchers can potentially use this same methodology, especially if they are able to identify the conglomerate divisions that are created via acquisition.

Another issue that we believe deserves attention in future research involves better understanding the relation between the economic event of diversifying through adding a business unit in a new industry and the accounting event of reporting a new business segment. Hayes and Lundholm (1996) suggest that segment reporting is often subject to strategic managerial motives, which calls into question the approach of defining corporate diversification strictly on the basis of the number of business segments. We have attempted to cover all the bases in our paper by examining firms that experience the accounting event of increasing the number of reported business segments, while also examining firms that experience the economic event of making a diversifying acquisition.

\section{REFERENCES}

Agrawal, Anup, and Jeffrey Jaffe, 2001, Do takeover targets underperform, Working paper, University of Alabama.

Andrade, Gregor, Mark Mitchell, and Erik Stafford, 2001, New evidence and perspectives on mergers, Journal of Economic Perspectives 15, 103-120.

Berger, Philip, and Eli Ofek, 1995, Diversification's effect on firm value, Journal of Financial Economics, 37, 39-65.

Burch, Timothy, and Vikram Nanda, 2001, Divisional diversity and the conglomerate discount: The evidence from spin-offs, Working paper, University of Miami.

Campa, Jose, and Simi Kedia, 1999, Explaining the diversification discount, Working paper, Harvard Business School.

Chevalier, Judith, 2000, What do we know about cross-subsidization? Evidence from the investment policies of merging firms, Working paper, University of Chicago.

Hasbrouck, Joel, 1985, The characteristics of takeover targets: $q$ and other measures, Journal of Banking and Finance 9, 351-362.

Hayes, Rachel, and Russell Lundholm, 1996, Segment reporting to the capital market in the presence of a competitor, Journal of Accounting Research 34, 261-279.

Hubbard, R. Glenn, and Darius Palia, 1999, A reexamination of the conglomerate merger wave in the 1960s: An internal capital markets view, Journal of Finance 54, 1131-1152.

Hyland, David, 2001, Why firms diversify: An empirical examination, Working paper, University of Texas, Arlington.

Kaplan, Steven, and Michael Weisbach, 1992, The success of acquisitions: Evidence from divestitures, Journal of Finance 47, 107-138.

Lamont, Owen, and Christopher Polk, 2001, The diversification discount: Cash flows versus returns, Journal of Finance 56, 1693-1721.

Lang, Larry, and René Stulz, 1994, Tobin's q, corporate diversification and firm performance, Journal of Political Economy 102, 1248-1280. 
Lang, Larry, René Stulz, and Ralph Walkling, 1989, Managerial performance, Tobin's $q$, and the gains from successful tender offers, Journal of Financial Economics 24, 137-154.

Lins, Karl, and Henri Servaes, 1999, International evidence on the value of corporate diversification, Journal of Finance 54, 2215-2239.

Loughran, Tim, and Anand Vijh, 1997, Do long-term shareholders benefit from corporate acquisitions? Journal of Finance 52, 1765-1790.

Maksimovic, Vojislav, and Gordon Phillips, 2001, The market for corporate assets: Who engages in mergers and asset sales and are there efficiency gains? Journal of Finance 56, 2019-2065.

Maksimovic, Vojislav, and Gordon Phillips, 2002, Do conglomerate firms allocate resources inefficiently across industries? Theory and evidence, Journal of Finance 57, 721-767.

Morck, Randall, Adrei Shleifer, and Robert Vishny, 1990, Do managerial objectives drive bad acquisitions? Journal of Finance 45, 31-48.

Piotroski, Joseph, 1999, The impact of newly reported segment information on market expectations and stock prices, Working paper, University of Michigan.

Plumlee, Marlene, and Jack Wolf, 2000, Purchase or pooling? The impact of accounting choice on the calculation of excess value, Working paper, University of Utah.

Rau, P. Raghavendra, and Theo Vermaelen, 1998, Glamour, value, and the post-acquisition performance of acquiring firms, Journal of Financial Economics 49, 223-253.

Schoar, Antoinette, 2000, Effects of corporate diversification on productivity, Working paper, Massachusetts Institute of Technology.

Servaes, Henri, 1996, The value of diversification during the conglomerate merger wave, Journal of Finance 51, 1201-1225.

Villalonga, Belén, 2000, Does diversification cause the diversification discount? Working paper, UCLA.

Whited, Toni, 2001, Is it inefficient investment that causes the diversification discount? Journal of Finance 56, 1667-1691. 